

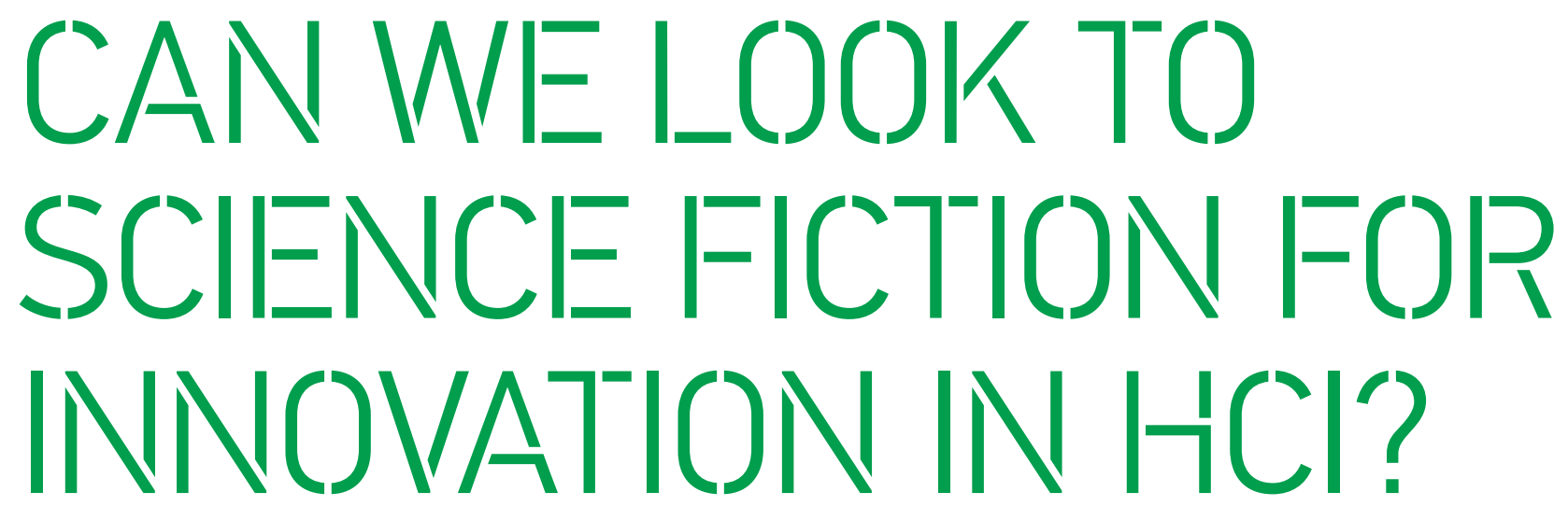

(4)

Daniel M. Russell, Google

Svetlana Yarosh, University of Minnesota

\footnotetext{
Insights

$\rightarrow$ Science fiction is

wonderful for inspiration

but should not be read

uncritically as a source

of design innovations.

$\rightarrow$ There is a tension

between design fiction

for speculative ideation

and design innovation

for pragmatic ideation-

we suggest a few heuristics

to help guide the pragmatic

use of design fiction.
}

We all want to invent the future. One approach to future invention is the notion that real design and science can be inspired by science fiction narratives, which define and illuminate user interaction issues [1]. Science fiction takes its future-facing ideas fairly seriously, and considerable ink has been spilled to argue for the ways in which science fiction gets the future right [2]. We commonly talk about a Blade Runner social dystopia and link current events and news about upcoming technologies as coming from, being derived from, or having been presciently predicted by science fiction. We may even aspire to emulate science fiction technologies by hosting competitions like Qualcomm's Tricorder XPRIZE, which aims to create a technology similar to the Star Trek tricorder device.

It's certainly tempting to imagine science fiction as a handy tool for invention. The implicit conceit is that this genre has a remarkable ability to give us visions of and foreshadow the science and technology of the future [3]. We all know about Star Trek holodecks or Minority Report-style hand-waving user interfaces: Are these serious science fiction envisionments of future UIs? Or do they subconsciously constrain our thinking by providing strong designs that are ever present? 
For this article, we broadly consider science fiction to be writing, movies, plays, games, and media of all kinds that is idea centered, science oriented, irreverent, iconoclastic, and engineering heavy. There are many subgenres within science fiction, which may take on different social structures, perspectives (e.g., utopian or dystopian), and technologies. For example, Afrofuturism, which blends the tropes of science fiction with global black culture; or the subgenre cyberpunk, characterized by combining the ideas of cybernetics with a punk aesthetic in a dystopian future. Common technical features of the latter include biologically integrated computer interfaces, advances in information technology, vast visually abstracted information spaces, artificial intelligence systems, and post-democratic societal control where corporations have more influence than governments. Here, we consider the role that science fiction may play in designing the future.

We argue that science fiction may provide a good grounding for discussion but is not a great source of accurate predictions of future technologies. These fictions fulfill their primary purpose of advancing the narrative and articulating a vision. They also frequently include common tropes and shortcuts that may limit rather than enhance envisioning the future. While a lot of science fiction seems prescient, there's a temptation to take it too literally, reading more into the literature than it should be expected to support. Given these limitations, we might ask: Is science fiction really a rich source of ideas, or is it merely a distraction, coaxing our eyes away from the prediction ball?

\section{PREDICTING THE FUTURE}

Science fiction as a genre deals not with a singular future, but rather with many possible futures. The futures that offer novel perspectives and ideas draw more readers. As a consequence, science fiction imagines many different kinds of worlds and technologies. We can certainly think of examples where a past science fiction narrative seems to eerily predict the current state [2]. But as a whole, how good is science fiction at predicting the future?

We all may have a confirmation bias that makes us more likely to remember those predictions that have been accurate than those that missed. Famously, some science fiction visions have come to pass: Fahrenheit 451's earbuds, Stand on Zanzibar's same-sex marriage, 1984's mass surveillance through technology, and countless stories that have presented variations of virtual reality, videophones, and mobile telephony.

However, science fiction for the most part missed out on predicting the powerful effects of social media, and it mispredicted technologies such as nuclear-powered interplanetary space travel (e.g., 2001: A Space Odyssey). Science fiction has predicted the establishment of a moon colony for every decade since the 1930s, yet those colonies are still in the indefinite future. In 1949, Robert Heinlein was famous for a set of 19 specific predictions published in Astounding magazine. He predicted that by 2000 , the housing shortage would be solved by new building technologies, that cancer and the common cold would be conquered, and that we would have explored the entire solar system and begun to venture beyond it. But only three of his 19 predictions proved correctmainly focused on his prediction of a mobile personal telephone that would record messages, answer queries, and transmit images. As a prediction mechanism, science fiction is effective at generating ideas, but not at linking them to a particular span of time or establishing their plausibility.

Of course, even nonfiction expert predictions of the future are frequently and spectacularly wrong. While some models like Moore's Law have proven robust, more than a few famous near-term serious predictions by practicing technologists have been incredibly inaccurate. "There is no reason for any individual to have a computer in his home," said Ken Olson, president, chairman, and founder of Digital Equipment Corporation (DEC), in a talk at a 1977 World Future Society meeting in Boston. Mary Meeker, writing a five-year projection of the number of people on the Internet,

underestimated by a factor of 2 , expecting 150 million Internet users would be online in 2001 when in fact over 300 million were online [4]. One review of 95 timeline predictions for AI from 1950 to 2012 found that most forecasts predicted general AI would be achieved "in the next 20 years" [5]. One of the most comprehensive reviews of technology forecasts during the past 50 years found that forecasts with time horizons beyond 10 years were rarely more accurate than coin flips [6].

The future is shaped by a diversity of factors that make it difficult to predict: unforeseen technical barriers, the creation of disruptive technologies, and economic or political changes that may prioritize some future world over others. If science fiction is to have a role in informing design, it must be leveraged with more nuance than a laundry list of future technologies.

\section{SCIENCE FICTION'S ANCHOR TO THE PRESENT}

One point to consider about interpreting science fiction as a conception of the future is that the design specifics are often biased by the context of the author. Instead of considering science fiction as a framework for making predictions about future tech, it may be more useful to see the creative act as an extension of the ideas of the time when it was written and as embedded within the cultural expectations of that time. For example, speculative fiction authored during the Victorian era tended to feature large ironworks with ornate decorations (e.g., the design of the submarine Nautilus in the works of Jules Verne). Closer to our time, the original Star Trek television series utilized 3D-bubble indicator lights and

As a prediction mechanism, science fiction is effective at generating icleas, but not at linking them to a particular span of time or" establishing their" plausibility. 
push-button designs on its bridge, an anachronistic sound of a teletype in the background, and tablets with orders that were carried to other parts of the ship by young ensigns. Each successive generation of the Enterprise bridge grew in sophistication as the technology of the current time advanced. The computer voice gained expressiveness and the ability to understand and answer complex questions, just as real computer voices improved. The bridge adopted visual display panels, just as personal computing was taking off in the writers' timeframe. Although the HCI aspects of science fiction can be impressively futuristic, the envisionments tend to be driven by combinations of the technology available to the writers and the needs of the particular narrative.

Social and cultural themes of the times also surface as science fiction conceptualizes a future world. The original 1960s Star Trek is well known for its focus on racial and species equity, which takes a specific stance on issues that were particularly salient at the time. Later Star Trek shows of the 1980s alluded to LGBT issues, which were pressing concerns in the decades following the Stonewall riots that took place in New York City in 1969. Classic science fiction, such as 1984 and Shock Wave Rider, are also very much products of the concerns of their times and authors, focusing on authoritarian governments and worries about computer control of public systems, respectively. However, one limitation of the past and current science fiction communities is that they disproportionately feature the contributions of a particular author demographic (i.e., white men). If we admit that visions of the future are influenced by the present context of the author, this is an important point to consider when adapting ideas from science fiction narratives.

While all literature is in some ways a reflection of its time, science fiction is conspicuously set in the future. As technologists and engineers, we may focus on the future-setting aspects of science fiction, but possibly to the detriment of understanding how it might be used as an interpretive lens for design. In fact, the priorities and concerns of the author's time and personal background end up biasing science fiction toward telling stories from the perspective of the present, rather than providing new insights and paving the way to future designs.

\section{OVERLY ACCEPTING SCIENCE FICTION TROPES}

Another limit of science fiction as a lens on the future is in taking common science fiction tropes and devices too literally. Some of the ideas of science fiction have become powerful memes, which we may adopt as design elements and usability patterns.

Science fiction incorporates many such tropes, including ideas that are implausible, just plain bad, or too good to be helpful. When reading a science fiction story, we don't worry about the plausibility of ideas that are necessary to advance the narrative. Antigravity, disintegrating ray guns, inertial dampeners, humanoid robots, universal translators, and faster-thanlight travel are all so commonly used for advancing the narrative that readers may stop critically considering whether these technologies or those that depend on their existence are actually physically feasible. Some ideas presented in science fiction are simply poorly executed, based on what we currently know about designing for people.

For instance, present fictional designs are extraordinarily complicated interfaces, such as Iron Man's dense heads-up display or Star Trek's poorly labeled touch interface. Many are inadvisable from an ergonomics perspective, such as Minority Report's transparent vertical interfaces, which required intense hand, arm, and shoulder movements. These choices are made for visual interest rather than to reflect a rigorous understanding of good user interface design.

Finally, some ideas in science fiction are "good" to the point of taking shortcuts rather than considering the "boring" design challenges. One insidious trope is that future user interfaces are all walk-up-and-use (even ones built by alien species!). Similarly, a common feature of many science fiction stories is the smooth, error-free integration of data from multiple sources. Writers just assume that data integration is a solved problem, but anyone who has spent time cleaning and merging data will attest to the opposite. The issue for design is that when commonplace ideas become tropes, we stop thinking about them critically and just use them in place of a more carefully worked-out idea. These ideas permeate our culture, potentially clouding our thinking about better, more plausible, and more innovative future designs.

\section{FROM SCIENCE FICTION TO DESIGN FICTION AND BEYOND}

Perhaps the role of science fiction is not to predict the future, but instead to consider possible futures. As Ursula K. Le Guin says, the future is a place where "anything at all can be said to happen without fear of contradiction from a native ... The future is a safe, sterile laboratory for trying out ideas in ... [it is] a means of thinking about reality, a method" [2]. This idea of fiction as a laboratory may have inspired the method of design fiction, first articulated by Bruce Sterling and Julian Bleecker in 2009 [1]. They propose that design fiction is science fiction that "makes more sense on the page" by fully fleshing out possible artifact designs and considering how they may be set in a particular time and place. This kind of diegeticprototype writing is at the core of design fiction, where the term diegetic places the emphasis on working out not only how something appears and operates, but also how it fits into the larger technology and social landscape [7]. Since Bleecker's and Sterling's essays were published, design fiction has become increasingly popular as an HCI ideation method [8]. The practice of design fiction is to envision a technology (in our case, with some kind of user interface) and then craft a story about how that is used, telling the tale more completely than a simple sketch, imagining it set in a particular use environment.

Design fiction is a promising extension of science fiction that may better serve the needs of designers as an envisionment method. However, there are important cautions to consider to prevent design from succumbing to the same issues that limit science fiction as a lens on the future. Based on our argument about the limits and strengths of science fiction, we provide five heuristics for the writers of design fictions and the designers who interpret those ideas: 
- Envision 5-10 years out rather than predicting a distant future. Predictions beyond five to 10 years quickly fade to the accuracy of coin tosses. It may be more tempting to resort to magical solutions (e.g., pain-free effortless data integration) rather than solving specific design challenges.

- Consider the writer's cultural context and how their experiences, demographics, and the concerns of the time may bias the technologies and social structures explored in the fiction.

- Question the use of common tropes that are ordinary in science fiction (e.g., humanoid robots) unless they are explicitly justified as a design choice.

- Evaluate the plausibility of proposed design ideas based on empirically known principles (e.g., ergonomics, physics).

- Imagine the downsides of the fictional tech. Science fiction has a long and rich history of imagining the failure modes of technology, social systems, and wellintentioned systems changes.

In industrial practice, design fiction tends to follow these guidelines to go from a clever idea to an innovative design that's pragmatic instead of an unimplementable, impossible blue-sky idea. Rather than working to "actively suspend disbelief in change" ([9], quoting Sterling), the use of design fiction in industrial practice seeks to devise and tell a compelling story about what could be believable and what could be implemented in the not too distant future. The design fiction artifacts created have a nearer-term perspective and a point of view that can be seen as an imaginative and organic extension of current practices. That is, the purpose of these design fictions is to show a path from now to then, with a plausible story (if not fully worked out at the moment) about how to go from the current state to the envisioned future technology. The story is a fiction, but still subject to critical review and analysis. The fiction informs us about what's just over the horizon - it's a way to see a bit further into the future with a speculative design that makes no implausible leaps depending on difficult-to-implement mechanisms like antigravity or instant walk-upand-use interface designs.

Both science fiction and design fiction can have a place in the designer's toolbox if approached with the appropriate caution. These are not a source of predictions, but rather laboratories for the exploration of possible worlds. These laboratories are reflections of the current priorities and cultural contexts - they may be biased by common tropes or memes that cloud rather than enhance the process of envisioning the future.

\section{CAN WE LOOK TO SCIENCE FICTION FOR INNOVATION IN HCI?}

It's clear that science fiction is a powerful force in the technologydevelopment world, and in our HCI design space in particular. Amit Singhal at Google is well known for reminding us that the Star Trek voice-driven computer inspired their work on voice-recognition, spoken actions, and question-answering support. Carl Sagan credits science fiction for sparking his interest in science. Science fiction also provides a set of ideas, language, and scenes that create a kind of common ground for people in the field. However, we've also described the limitations of looking to science fiction for HCI innovation. We provide evidence counter to the popular media narrative that science fiction may be a source of predictions of future technologies. We also caution readers to consider how a fiction may be biased by the context of its author or may fall prey to common tropes that lead to implausible, bad, or "magical" solutions. It is important to consider whether a particular technology posited in a science fiction narrative is an actual proposal of a future design or simply a trope driving the narrative.

That said, we do see a substantial potential role for fiction in driving design. Science fiction can be sources of inspiration, common language, and both aspirational and cautionary tales. Used with appropriate discretion, science fiction can inspire experts in creating design fictionstories whose primary purpose is to elaborate and explore new technologies in their context. Seen from this point of view, science fiction has the opportunity to be the most vibrant and valuable of all literary genres. It is an invaluable way to think, design, and create a positive future.

\section{ACKNOWLEDGMENTS}

Many thanks to all of the attendeesand in particular those who commented critically - at our presentation of these ideas at the Human-Computer Interaction Consortium meeting in June 2017. We wove these stories while strolling along the silicon dioxide beaches of Monterey County in California.

\section{ENDNOTES}

1. Sterling, B. Design fiction. Interactions 16, 3 (2009), 20-24.

2. Gunn, W. How America's leading science fiction authors are shaping your future. Smithsonian Magazine (2014).

3. Marcus, A. The history of the future: Sci-fi movies and HCI. Interactions 20, 4 (2013), 64-67.

4. Meeker, M. The Internet Report. HarperCollins Publishers, 1996.

5. Armstrong, S., Sotala, K., and ÓhÉigeartaigh, S.S. The errors, insights and lessons of famous AI predictions - and what they mean for the future. Fournal of Experimental (t) Theoretical Artificial Intelligence (May 20, 2014).

6. Mullins, C. Retrospective Analysis of Technology Forecasting.

The Tauri Group, 2012.

7. Kirby, D. The future is now: Diegetic prototypes and the role of popular films in generating real-world technological development. Social Studies of Science 40, 1 (2010), 41-70.

8. Dourish, P. and Bell, G. 'Resistance is futile': Reading science fiction alongside ubiquitous computing. Personal and Ubiquitous Computing 18, 4 (2014), 769-778.

9. Bosch, T. Sci-Fi Writer Bruce Sterling explains the intriguing new concept of design fiction. Future Tense Web magazine (Mar. 2012); http://www.slate.com/blogs/ future_tense/2012/03/02/bruce_sterling on_design_fictions_html

Daniel M. Russell is a senior research scientist at Google in the Search Quality group, working to understand how people search for information online. He has been reading and viewing science fiction since the days when Star Trek TOS first aired.

$\rightarrow$ drussellagoogle.com

Svetlana (Lana) Yarosh is an assistant professor in the Department of Computer Science and Engineering at the University of Minnesota. Her research focuses on embodied interaction in social computing systems. She is also an unrepentant Trekkie.

$\rightarrow$ lanaQumn.edu 